\title{
As multiplicidades rizomáticas do sujeito-surdo-social-plural no processo de letramento bilíngue
}

The rhizomatic multiplicities of the subject-deaf-social-plural in the process of bilingual literacy

Las multiplicidades rizomáticas del sujeto-sordo-social-plural en el proceso de alfabetización bilingüe

\section{Ângela Simone Mattos Esteves}

Mestra pela Universidade Federal Fluminense, Niterói, Rio de Janeiro, Brasil.

angelasimone73@gmail.com

ORCID - https://orcid.org/0000-0003-4037-9599

Ruth Maria Mariani Braz

Professora doutora na Universidade Federal Fluminense, Niterói, Rio de Janeiro, Brasil. ruthmariani@yahoo.com.br

ORCID - https://orcid.org/0000-0003-2224-9643

Dagmar de Mello e Silva

Professora doutora na Universidade Federal Fluminense, Niterói, Rio de Janeiro, Brasil.

dag.mello.silva@gmail.com

ORCID - https://orcid.org/0000-0002-5863-3607

Recebido em 27 de fevereiro de 2020

Aprovado em 14 de novembro de 2020

Publicado em 21 de dezembro de 2020

\section{RESUMO}

Este é um estudo de caso atravessado por uma cartografia aqui apresentada como campo de forças e relações que nos faz refletir. Portanto, trata-se muito mais de agenciamentos sociais e científicos que transformaram modos de pensar do que propriamente de proposições a respeito de métodos adequados de como ensinar o Português para os surdos. Arriscaríamos dizer que este foi um trabalho auto formativo, que foi se desdobrando ao longo do tempo, mostrando-nos que precisamos dar continuidade ao processo de cartografar e "desemaranhar" as múltiplas linhas que enredam a teia histórica que separa surdos de ouvintes. Concluímos que as pessoas surdas também necessitam de metodologias diferenciadas que devem ser usadas por professores nas aulas, respeitando a sua singularidade linguística. Nem todos os surdos partem do mesmo ponto no ato de aprender e não dispõem dos mesmos recursos para isso. A análise desses registros nos permitiu observar a criação do ato de pensar. Sendo assim, este trabalho teve, também, a intenção de produzir cartografias possíveis desses processos através de registros manifestos do ato de pensar e, a partir disso, a construção das reflexões sobre o aprender que transcende o que se faz materialmente na sala de aula.

Palavras-chave: Escrita, Cartografia, Enunciação. 
http://dx.doi.org/10.5902/1984686X42625

\section{ABSTRACT}

This is a case study traversed by cartography here. As a field of forces and relationships that make us reflect. Therefore, it is much more about socials and scientific assemblages than transforming ways of thinking than properly proposing proposals regarding the methods used to use Portuguese for the deaf. We would venture to say that this was an automatic formatting work, which unfolded over time, showing that it is necessary to detect the process of mapping and "unraveling" as the various lines that include a historical history that separates the ears. Conclude that people with deafness also use different methods that should be used by teachers in class, respecting their linguistic uniqueness. Not all deaf people make the same point in the act of learning and do not have the same resources for this. The analysis of these records allowed us to observe the creation of an act of thinking. Therefore, this work also had the intention of producing possible cartographies of these processes through manifest records of an act of thinking and, from there, a construction of reflections on the learning that transcends or causes material in the classroom.

Keywords: Writing, Cartography, Enunciation.

\section{RESUMEN}

Este es un caso de estudio atravesado por la cartografía aquí. Como un campo de fuerzas y relaciones que nos hacen reflexionar. Por lo tanto, se trata mucho más de ensamblajes social y científica que de transformar formas de pensar que de proponer adecuadamente propuestas sobre los métodos utilizados para usar el portugués para sordos. Nos aventuraríamos a decir que este fue un trabajo de formateo automático, que se desarrolló con el tiempo, lo que demuestra que es necesario detectar el proceso de mapeo y "desentrañamiento" como las diversas líneas que incluyen una historia histórica que separa los oídos. Concluya que las personas sordas también usan diferentes métodos que los maestros deberían usar en clase, respetando su singularidad lingüística. No todas las personas sordas hacen el mismo punto en el acto de aprender y no tienen los mismos recursos para esto. El análisis de estos registros nos permitió observar la creación de un acto de pensamiento. Por lo tanto, este trabajo también tenía la intención de producir posibles cartografías de estos procesos a través de registros manifiestos de un acto de pensamiento y, a partir de ahí, una construcción de reflexiones sobre el aprendizaje que trasciende o causa material en el aula.

Palabras clave: Escritura, Cartografía, Enunciación.

\section{A construção cognitiva e a não linearidade}

Ao intentarmos uma reflexão sobre os processos de aprendizagem da língua portuguesa escrita pela pessoa surda, tomaremos como princípio a não linearidade da função simbólica na Língua de Sinais. Entendemos que essa perspectiva nos ajuda a pensar a respeito de como relações textuais imagéticas podem auxiliar no entendimento das diferentes produções de sentidos de surdos e suas múltiplas formas de aprendizagem 
http://dx.doi.org/10.5902/1984686X42625

da Língua Portuguesa escrita. Isto porque os modos de leitura de um usuário de Língua de Sinais são diferentes das construções de um falante de língua oral-auditiva, pois, em Libras, dois sinais podem ser reproduzidos ao mesmo tempo, enquanto em línguas orais-auditivas os signos estão presos à linearidade dos significados. Sendo assim, os textos em Língua Portuguesa, quando desenvolvidos em propostas educativas baseadas na visualidade da surdez, devem respeitar a experiência visual dos surdos, tornando o entendimento do texto mais autônomo para esses leitores.

Sob a perspectiva sócio interacionista (VYGOTSKY, 2000), é na linguagem e nas interações sociais que se encontra a gênese do desenvolvimento cognitivo. Estamos de acordo, com essa perspectiva, por pensarmos que nossas existências são atravessadas pelos diversos contextos históricos e culturais em que estamos inseridos. Porém, fica a questão: Como explicar os diferentes modos pelos quais somos atingidos por esses contextos? Se fôssemos atingidos da mesma forma, teríamos que supor que todos nós somos constituídos por uma mesma essência, através da qual seria possível alcançar ou produzir verdades, modos apropriados de ensinar e aprender, por exemplo. Vygotsky (2000), responde a essa questão apontando a micro gênese como um dos planos do desenvolvimento que se caracteriza pela emergência do psiquismo individual no cruzamento dos fatores biológicos, históricos e culturais. Este plano genético centra-se em fatores Inter dispõem e se utilizam de gritos, expressões faciais, choro etc. para entrar em psicológicos em que aspectos relacionados à afetividade assumem um papel crucial. Portanto, a micro gênese é também o estudo da origem e da história de um evento particular que deriva da natureza psicológica da pessoa que, por sua vez, se constitui pelo conjunto das relações sociais transferidas para seu mundo interno, ou seja, são as relações sociais internalizadas que constituem o sujeito na dialética indivíduo-sociedade.

Apesar de Vygotsky apontar uma alternativa epistemológica para a questão aqui, inicialmente formulada, é com Deleuze (2003) que vamos encontrar apaziguamento para essa aporia, posto que em Vygotsky, as relações constituintes do sujeito se dão no campo das representações do mundo pela linguagem e, nessa perspectiva, os signos são aprisionados em significados, na linguagem, que por sua vez constituem as funções psíquicas superiores. Já em Deleuze, é a linguagem que coloca o mundo em funcionamento e não apenas o representa (MOSTAFA, 2008). 
http://dx.doi.org/10.5902/1984686X42625

Assim, Deleuze nos aponta a resposta para esse impasse, destacando que o estilo seria o modo através do qual se traduzem ou se interpretam os diferentes encontros entre signos:

\begin{abstract}
Cada sujeito exprime o mundo de um certo ponto de vista. Mas o ponto de vista é a própria diferença, a diferença interna e absoluta. Cada sujeito exprime, pois, um mundo absolutamente diferente e, sem dúvida, o mundo expresso não existe fora do sujeito que o exprime (o que chamamos de mundo exterior é apenas a projeção ilusória, o limite uniformizante de todos esses mundos expressos). Mas o mundo expresso não se confunde com o sujeito: dele se distingue exatamente como a essência se distingue da existência e inclusive de sua própria existência. Ele não existe fora do sujeito que o exprime, mas é expresso como a essência, não do próprio sujeito, mas do Ser, ou da região do Ser que se revela ao sujeito (DELEUZE, 2003, p. 4041).
\end{abstract}

O estilo é responsável por mostrar como o mundo se revela ao sujeito e é por isso que a busca da verdade é sempre paradoxal, posto que, mesmo que sejamos atravessados pelos mesmos contextos sócio-históricos, "cada sujeito exprime um mundo absolutamente diferente" (DELEUZE, 2003, p. 41), ou seja, o mundo se revela a cada um, sob diversos pontos de vista, e isto depende da forma como os signos nos atravessam.

Saussure (1995), propõe que o aspecto social se refere ao uso comum da língua, que é tratada por ele, como um sistema fechado em si mesmo e a fala como um aspecto individual da linguagem. Esse entendimento da língua, não leva em consideração que as palavras têm significados em seus respectivos contextos de interação social e, mais ainda, há que se considerar os estilos e respectivos processos de singularização que nos diferenciam uns dos outros. Por isso optamos pelo diálogo com Bakhtin (1990), para quem os signos são essenciais na construção da consciência. O processo de consciência do indivíduo ocorre mediante a apropriação e utilização dos signos em suas relações sociais. Diante do exposto, a perspectiva desse estudo parte da premissa de que o processo de aquisição da linguagem não se basta como um domínio das regras gramaticais da Língua Portuguesa.

Os estudos de Fernandes (1990), Vigostski (2000), Goldfeld (2002) e Dolle (2011) mostram que crianças surdas ou ouvintes não falam ao nascerem, mas dispõem e se utilizam de gritos, expressões faciais, choro, etc para entrar em contato com seu meio e esse meio Ihes solicita que façam e respondam essas interações sociais.

Se observarmos bebês em seus processos miméticos de apropriação das expressões de seus interactantes, vamos perceber que essas relações contribuem para que eles criem suas próprias formas de expressar os estados interiores. Segundo Dolle (2011), isso 
equivale a dizer que nesse processo de maturação dos centros nervosos; como lobos parietais do cérebro, responsáveis pela fala, pela audição e pelo comando nervoso das estruturas laríngeas, ocorre uma multiplicação dos meios de comunicação, sempre reforçados pelo exercício pessoal e pelas solicitações do mundo exterior.

As manifestações expressivas dos bebês, suas modulações que contribuem para expressar seus estados interiores, se não reforçados por seu meio social, tendem a diminuir pouco a pouco, por isso, é fundamental que a família do surdo domine a Língua de Sinais para que o bebê continue seu processo de aquisição de linguagem (QUADROS, 1997).

No processo de aquisição de linguagem do surdo, faz-se necessário entender e estimular a Língua de Sinais, pois, através da apropriação contextualizada, da compreensão de seus valores sociolinguísticos, cientes da história de preconceitos, marginalizações e proibições vivenciadas historicamente pelos surdos, ele poderá utilizar os signos com as intensidades e efeitos de comunicabilidade dos falantes da língua oral. Afinal, ele também participa e interage com o meio em que vive.

O usuário de uma língua percebe sua gramática de forma inconsciente, o que lhe importa é o conteúdo do que ele diz. Logo, a aquisição da linguagem das pessoas surdas ou ouvintes não pode ser pautada apenas nas regras gramaticais (QUADROS, 1997). São inúmeros os processos criados pelas crianças antes que consigam se comunicar oralmente ou em sinais. É fundamental a interação entre os interlocutores no ato comunicacional. Conforme Dolle (2011), a linguagem pode ser definida como a capacidade de se comunicar com o outro através de símbolos e de signos, é adquirida pela atividade estruturo-funcional do sujeito que a constrói, ao mesmo tempo em que se constrói, com o auxílio do sistema de sinais posto à sua disposição no(s) seu(s) ambiente(s) de vida.

À medida que as estruturas cognitivas do indivíduo progridem, a capacidade de formar classes transforma os significados individuais em coletivos, ou seja, quanto maior sua percepção, seu estímulo, a interação, a realização com o meio social em que o indivíduo estiver imerso, mais será permitida a ele, surdo ou ouvinte, a validação dos signos dados à polivalência e polissemia da linguagem.

A interação entre os pares é constituída nessas relações sociais baseadas nos signos linguísticos. O que se vê é que a maioria das crianças surdas oriundas de pais ouvintes e a falta de experiência com a surdez, faz com que esses pais e demais familiares apresentem dificuldades em relação às formas de comunicar-se com essas crianças. 
http://dx.doi.org/10.5902/1984686X42625

Segundo Bakhtin (1990), os signos linguísticos só emergem, decididamente, do processo de interação entre uma consciência individual e outra. E a própria consciência individual está repleta de signos. A consciência só se torna consciência quando se impregna de conteúdo ideológico (semiótico) e, consequentemente, somente no processo de interação dos signos e significados de sua cultura. Logo, a pessoa surda não apresentaria tantas dificuldades em seu processo de aquisição de língua se não fossem os meios sociais. Essas dificuldades não estão necessariamente no indivíduo surdo ou na sua impossibilidade de ouvir, a pessoa surda possui as condições necessárias para constituirse enquanto existência singular no sentido social da linguagem. Ele é um ser social, que sinaliza em contextos polifônicos e pode ser reconhecido através de seus textos.

Para além dessas teorizações a respeito da construção social da língua, não podemos nos esquecer da existência de dispositivos sociais que muitas vezes atuam como agenciamentos coletivos de enunciação, segundo Deleuze e Guattari (2011).

Um agenciamento é precisamente este crescimento das dimensões numa multiplicidade que muda necessariamente de natureza à medida que ela aumenta suas conexões. (DELEUZE, 2011. p.16)

Toda existência se constitui por agenciamentos em um mundo híbrido, de produções maquínicas de subjetividades e singularidades, dando origem a diferentes formas de compreender o mundo, configurando modos de existência singulares na formação cultural e organização social. Deleuze e Guattari propõem repensar a subjetividade humana através de peças que se acoplam a partir dos encontros que elas operam. Talvez aqui esteja um dos enigmas em relação às dificuldades que surdos apresentam na aquisição da Língua Portuguesa. Estaríamos nós, educadores, apenas considerando o contexto histórico e social e deixando à deriva desse processo, aspectos relacionados aos modos próprios de existência das pessoas surdas em seus encontros com as "peças" do mundo?

Afinal, conforme nos propõe El Khouri (2011),

As palavras não são ferramentas, elas são o próprio ato de ordenação. $A$ construção das frases remete ao seu sentido: a semântica determina a sintaxe, e não o contrário. As regras gramaticais se originam em função do sentido da fala. A linguagem, portanto, é pragmática, e as outras dimensões da linguagem (semântica, sintaxe, fonética) estão a ela submetidas. Por isso a fala deve estar obrigatoriamente inserida em um dado contexto para ter sentido. A linguagem é, assim, circunstancial (EL KHOURI, 2011, p.07).

Diante do exposto, cabe a questão: não estariam os surdos nos apontando que nossos modos de ensinar não estariam produzindo agenciamentos potentes e que, portanto, essa forma de comunicar não Ihes faz sentidos? 
http://dx.doi.org/10.5902/1984686X42625

\section{Metodologia}

Como método de pesquisa, a cartografia foi pensada por Gilles Deleuze e Félix Guatarri (2011) como um percurso de pesquisa coerente com a perspectiva processual de seus estudos, qual seja, pensar a respeito dos processos e produção de subjetividade em um contexto capitalista.

Originalmente, o conceito de Cartografia está relacionado às inquietações inerentes aos seres humanos em conhecer o mundo e os sentidos das coisas que vivenciam. Etimologicamente, o termo se refere à descrição de cartas. Essa concepção que a palavra traz na sua origem nos aponta a ideia de traçados de mapas (PASSOS, 2009). Geograficamente, Cartografia é uma ciência que se destina à habilidade de elaborar mapas, cartas ou outras formas de representar, descrever ou detalhar objetos, fenômenos, ambientes físicos e socioeconômicos (PASSOS, 2009).

Esses princípios foram inspirações de Giles Deleuze e Félix Guatarri (2011) para conceberem a Cartografia como método que desse respaldo às proposições da Esquizoanálise, teoria criada por eles, que se contrapõe àquilo que consideram um reducionismo da teoria psicanalítica e que, segundo os autores, aprisiona as produções do inconsciente ao drama edípico.

Desse modo, Giles Deleuze e Félix Guatarri (2011) buscaram nos princípios da Cartografia uma forma de dar suporte científico às noções de "eu" e de subjetividade concebidas por eles como devires, em movimento e em produção, em meio à multiplicidade, compondo territórios rizomáticos e diversos.

\footnotetext{
Assim, através do método cartográfico, Deleuze e Guatarri tentam demonstrar como as multiplicidades ultrapassam a distinção entre a consciência e o inconsciente, entre a natureza e a história, o corpo e a alma. As multiplicidades são a própria realidade, e não supõem nenhuma unidade, não entram em nenhuma totalidade e tampouco remetem a um sujeito. As subjetivações, as totalizações, as unificações são, ao contrário, processos que se produzem e aparecem nas multiplicidades (DELEUZE; GUATARRI, 2011, p. 10).
}

Tendo em vista esses pressupostos, optamos pela Cartografia, posto que a pesquisa aqui realizada não pretendeu se ater a modelos eminentemente demonstrativosrepresentacionais que não se adequavam ao teor processual de nossos estudos.

Como afirma Fernandes (1990), sob o ponto de vista da natureza do pensamento, da experiência, da lógica natural e dos princípios da linguagem, os parâmetros que servem ao estudo da linguagem pelo surdo não são os mesmos da criança ouvinte. Seja por obedecer 
a um princípio diverso ou por diferença na maturidade psíquica em relação aos primeiros anos de vida, seja pela natureza mesma das diferenças de experiências, o fato é que tais princípios foram ativados de outro modo no que tange o desenvolvimento da linguagem. Cabe discernir que estímulos são adequados à realidade do surdo para que possa conseguir o desenvolvimento da linguagem em todas as suas potencialidades. Nesse sentido, optou-se pela contribuição da cartografia para o desatamento de alguns nós que possam ajudar a puxar alguns fios desse emaranhado, para continuarmos tecendo espaços de encontros entre signos.

Pretendeu-se, portanto, nesta pesquisa, cartografar como o letramento visual1, pode contribuir para a aprendizagem de Língua Portuguesa escrita (L2) por surdos adolescentes/adultos descartando qualquer linearidade de percurso e optando pelas multiplicidades de linhas presentes nesse traçado.

A Cartografia como Abordagem Metodológica, aponta como princípio a metáfora do Rizoma como analogia do pensamento múltiplo, das diferentes conexões de ideias, característica fundante desta abordagem. A pesquisa cartográfica é regida segundo alguns norteadores. São eles:

A heterogeneidade, que ressalta a natureza rizomática desta forma de investigação, considerando as diferentes possibilidades de conexões de saberes que podem surgir ao longo do processo de pesquisa, indicando que as vivências dos envolvidos na pesquisa irão interferir diretamente em seu curso e nos pontos importantes a serem observados.

A multiplicidade, na qual o pesquisador se debruçar sobre os elementos de investigação lançando seu olhar sobre as singularidades e relações, que são seus "devires" (DELEUZE, GUATTARI, 1995), distanciando-se de um olhar que propõe a polarização de ideias e perspectivas, valorizando o movimento pelo qual as coisas se transformam.

A ruptura a-significante que reconhece que as rupturas podem ocorrer a qualquer momento mudando os rumos da pesquisa.

Por fim, destacamos a própria cartografia, como um dispositivo ético/estético de entender e encaminhar a pesquisa, pois, é a partir das questões-problema que surgem ao longo do processo, que a pesquisa irá se desenhar.

Para colocar a pesquisa em movimento, foram realizadas oficinas, que procuram respeitar as singularidades linguísticas dos participantes em que o trabalho de letramento com a pessoa surda adolescente/adulta pudesse ter coerência com nosso percurso teórico até aqui. 
http://dx.doi.org/10.5902/1984686X42625

Assim, tentando promover agenciamentos para uma educação cujos movimentos estão em vias constantes de se refazerem, onde "aprender" e "ensinar", se constituem em atos dialógicos entre quem ensina e quem aprende, entre aquilo que vemos e o que pode nos fazer ver de modo diferente. Apostamos numa perspectiva de pensamento, que mais do que representação das coisas dadas, nos interessava a possibilidade de criação de novos mundos.

Tratou-se, assim, de liberar-se das imposições de métodos como "caminhos para as verdades" e ser afetado pelo conhecimento como algo que nos acontece. É esse acontecimento que permite a elaboração rizomática de uma educação que foge dos modelos de linhas retas.

Neste caminho, apresentou-se aos alunos surdos da sala de recursos multifuncionais livros de literatura cujos enredos eram narrados apenas através da linguagem não verbal. A proposta solicitada consistiu na leitura individual de uma determinada obra literária escolhida. Após essa primeira leitura, foi-lhes solicitado que relatassem por escrito, de forma geral, tudo que fora lembrado do enredo. Ao término deste processo, foi realizada a releitura do livro escolhido, consultando página por página, para que escrevessem sobre cada cena observada no enredo.

A observação dos registros escritos realizados pelos alunos após a leitura dos textos escolhidos promoveu reflexões sobre como foi a construção do ato de pensar desses alunos. Quais foram os caminhos por eles trilhados para construírem aqueles registros, tendo em vista que as interpretações, muitas vezes diferiam das respostas previsíveis e esperadas, sobre os enredos dos livros apresentados.

Compreendemos então, que cada um com suas diferentes maneiras de "ver" os textos que Ihes foram apresentados; produziram leituras próprias. Alguns criaram uma nova versão, outros mudaram os rumos das histórias e transitaram para outros caminhos. Entendemos que o que em princípio era visto como fora de contexto, poderia ser compreendido, tal qual citado por Calvino (1990), por "outra ótica, outra lógica, outros meios de conhecimento e controle" que fogem, escorregam, abrem brechas, apontando a complexidade de um processo que está muito além de respostas pré-concebidas ou das experimentações que aguardam por bons resultados.

Como exemplo de nossa cartografia, podemos citar um determinado aluno que após ler o livro Catando Feijão de Liliane Romanelli em que a história é elaborada somente através da linguagem não verbal, escreve sobre a história lida. Nesse registro escrito o 
http://dx.doi.org/10.5902/1984686X42625

aluno faz uma listagem de palavras. O único sintagma em que se apresenta o registro de uma ação é justamente aquele que se equivale ao título da obra lida, que consta em sua capa.

Em um segundo momento, com o intuito de obter um registro mais detalhado sobre cada cena analisada no livro, o aluno leu o livro Cena de rua de Angelo Lago, elaborado apenas com linguagem não verbal e, consultando página por página, ele escreveu sobre cada cena observada no enredo. Esse registro, já apresenta uma estrutura sintática da língua portuguesa mais complexa do que no primeiro momento. Há o emprego de verbos, de conjunções, pronomes, concordância sintática, enfim uma estrutura frasal mais próxima do que se apresenta na norma culta sintática da língua portuguesa escrita.

Nesses dois primeiros momentos, o aluno antes de fazer o seu registro escrito em Língua Portuguesa teve acesso ao texto literário apenas pela obra literária impressa. Ele acessou as informações contidas na história observando as ilustrações em linguagem não verbal que compunham esse enredo. As únicas sinalizações presentes nessas interlocuções que precederam os registros em Língua Portuguesa, ocorreram em relação às orientações sobre o que era para ser feito nas propostas apresentadas. Ou seja, observar o livro, analisar a história e escrevê-la em Língua Portuguesa, na folha em branco.

Em um terceiro momento, o aluno assiste a um DVD em Libras (Língua Brasileira de Sinais) sobre a história "A Cartomante" de Machado de Assis. Essa narrativa no DVD é apresentada com uma imagem de um texto em Língua Portuguesa escrita à direita da tela e uma pessoa a esquerda do monitor que sinaliza toda essa narrativa apresentada ao lado. Não há nenhum outro recurso de imagem além desses aqui descritos. Não há cenário, representação de personagens, nada disso, apenas um narrador sinalizando o conto. Em menos de cinco minutos, o aluno já estava disperso e sinalizando que não entendia a história. Interrompeu a proposta e recusou-se a escrever a respeito do pouco que assistiu, pois sinalizou que não entendeu nada.

Em um quarto momento, apresentamos um outro DVD em Libras. Nesse a interpretação se difere da anterior, há toda uma representação de cena concomitante a narrativa. A história é contada em Libras através da dramatização dos elementos que constituem seu enredo. Após a contação em DVD da história dramatizada e em Libras, houve a mesma solicitação de seu registro em Língua Portuguesa escrita. Nesse registro, evidencia-se uma estrutura frasal mais complexa daquelas elaboradas nas situações anteriores, observa-se até a elaboração de períodos compostos. 
http://dx.doi.org/10.5902/1984686X42625

Na sequência, solicitamos que o aluno lesse o livro com a mesma história do último DVD e realizasse o registro com consulta à história em análise. $\mathrm{O}$ aluno fez um registro linguístico representando as falas nos balões e demonstrou com isso um entendimento maior do contexto discursivo, além de apresentar o registro de cenas em que ocorre o diálogo através de suas ilustrações. Vale ressaltar que o texto literário em análise está todo escrito com a presença de um narrador em $3^{\underline{a}}$ pessoa.

Os registros apresentados pelo aluno indicam a apropriação e transposição dos conceitos de discurso indireto para discurso direto. A análise dessa experiência de leitura e escrita com o aluno surdo provocou o encontro com um problema, rompeu-se com naturalizações na forma como o ensino dessa escrita vem sendo conduzido. $O$ aluno surdo registrou palavras em Língua Portuguesa com uma estrutura diferenciada. Com isso passamos a entender que esse aluno precisa ser incentivado a se lançar nesse processo de leitura e escrita, tal como o "egiptólogo" proposto por Deleuze; "a decifrar signos", de modo a ser capaz de entrar em sintonia com esse processo e buscar seus próprios caminhos (DELEUZE, 2003).

Nesse percurso pudemos repensar sobre o que é aprender, algo que precede qualquer modelo instrucional e que pode nos ajudar nessa complexa tarefa de ensinar a fim de potencializar novos caminhos para processos de aprendizagens, seja com alunos surdos e/ou ouvintes.

Diante dessas reflexões sobre as especificidades da língua e de sua aquisição, vemos a necessidade de um novo olhar sobre as construções textuais já que os signos, em língua de sinais, não se constroem a partir de sons que se combinam, mas de mãos que se movimentam no espaço e que podem se organizar de forma simultânea e não-linear.

Essa não linearidade da construção da língua de sinais e a não linearidade no processo da função simbólica nos oferece pistas sobre a importância relação textual imagética para o surdo. Fazer um texto escrito com sua forma gráfica em árvore, em teia, em mapa de história ou em história em quadrinho como propõe Lebedeff (2010) pode auxiliar o surdo na construção de uma melhor elaboração da função simbólica, ou seja, pode contribuir para que o surdo distinga melhor os sistemas de significações de seu contexto social, mesmo que não nos assegure um determinado aprendizado que é singular.

Partimos do corpo para chegar às letras assim como partir do simbólico para o concreto e vice-versa a partir de suas próprias experiências é certamente um diferencial importante na relação da pessoa surda com a escrita e isso deve repercutir nas 
apropriações que esse sujeito fará desse objeto. Mas não podemos esquecer que ao longo dessa escrita aprendemos com Deleuze que:

Quando perguntamos 'que é orientar-se no pensamento', aparece que o pensamento pressupõe ele próprio eixos e orientações segundo as quais se desenvolve, que tem uma geografia antes de ter uma história, que traça dimensões antes de construir sistemas (DELEUZE, 2007, p.130).

Buscamos dialogar com os pressupostos teóricos que embasam o entendimento de que a língua portuguesa para a pessoa surda brasileira é, de um modo geral, sua segunda língua, o que significa que os processos de aprendizagem de leitura e escrita da pessoa surda têm como suporte a sua língua primeira, Libras. Assume-se aqui que é importante repensar esses processos em uma perspectiva de letramento visual tal como apresentada por Lebedeff (2010) assim como refletir sobre o que é pensar e o que é aprender em Deleuze (2003; 1998).

\section{Resultados e Discussão}

\section{A língua, a linguagem e o pensamento}

As línguas apresentam características próprias além do conteúdo e do contexto sóciohistórico. A estrutura gramatical de um pensamento expresso em Língua de Sinais muito provavelmente será realizada de forma diferente em outra língua. No caso da Língua de Sinais, ainda há o aspecto de ser uma língua espaço-viso-manual.

Dados aos aspectos sobre aquisição de linguagem, apresentados no início desse artigo e, em se tratando especificamente de pessoas surdas; fundamentadas nos estudos de Sanches (1991), Quadros (1997) e Skliar (1998), defendemos a Educação Bilíngue. De acordo com Fernandes e Rios (1998), Educação Bilíngue é entendida pelo pressuposto da necessidade da pessoa surda fazer uso de sua língua materna (Língua de Sinais) e ter acesso à língua usada pelos ouvintes de seu país. Educação numa perspectiva bilíngue não é, em essência, uma nova proposta educacional em si mesma, mas uma proposta de educação em que o bilinguismo atua como possibilidade de interação do indivíduo ao meio sociocultural a que pertence, ou seja, às comunidades de surdos e de ouvintes.

Segundo esses pressupostos, educar na perspectiva do bilinguismo é "cuidar" para que se garanta a emancipação de surdos frente a processos comunicacionais, em que as línguas se mostrem instrumentos indispensáveis de interação no mundo. A aquisição 
http://dx.doi.org/10.5902/1984686X42625

desses sistemas linguísticos deve ocorrer o mais cedo e o mais breve possível, considerando-se a Língua de Sinais como primeira língua, na maioria dos casos.

Os pesquisadores que defendem a perspectiva bilíngue de ensino orientam as famílias de crianças surdas para aprendizagem e o contato com a Língua de Sinais. Fernandes (1990) explica sobre bilinguismo composto2, em que a aprendizagem da segunda língua ocorre em situação formal e bilinguismo coordenado3, quando ocorre aquisição das línguas em situações informais diferentes. De acordo com Megale (2005),

Deve ser enfatizado que um indivíduo bilíngue pode ser ao mesmo tempo mais composto para certos conceitos e mais coordenado para outros. A distinção feita a partir da organização cognitiva é comumente mal interpretada, posto que esta distinção não se refere a diferentes níveis de competência linguística, a diferenças entre a idade de aquisição das línguas ou a diferentes contextos de aquisição. Embora haja uma grande ligação entre o tipo de organização cognitiva, idade e contexto de aquisição, não existem correspondência direta entre a forma de representação cognitiva e idade de aquisição da língua. É verdade, porém, que um indivíduo que aprendeu as duas línguas quando criança no mesmo contexto, provavelmente apresenta uma única representação cognitiva para duas traduções equivalentes. Enquanto um indivíduo que aprendeu a L2 em um contexto diferenciado da sua L1 pode apresentar representações distintas para duas traduções equivalentes (MEGALE, 2005, p.5).

Cabe ressaltar que são sistemas conceituais paralelos e independentes e a criança vai adquirir esses conceitos e valores das palavras, distinguindo-as de outras palavras da mesma língua, resguardadas as características culturais dessa língua.

Essas reflexões relacionadas à aquisição de linguagem mostram a responsabilidade das famílias ouvintes de bebês surdos, no sentido de aprenderem a Língua de Sinais para que o bebê possa construir seu processo de aquisição de linguagem em um ambiente de comunicação bilíngue que lhe permita "penetrar no universal das relações que constituem a ideia e nas singularidades que lhes correspondem" (DELEUZE, 1998, p. 236-237). Nesse sentido, Deleuze (1998) nos dá subsídios para pensar possíveis caminhos pelos quais surdos e ouvintes possam construir um campo Inter relacional em que as diferentes formas semióticas dos interlocutores se relacionem com suas linguagens e estejam em patamar de igualdade no ato comunicacional.

Foi muito mais o desafio de decifrar alguns enigmas que nos levam à formulação dessas questões que procuramos pensar a respeito de fatores inerentes à aprendizagem de uma língua não nativa (no caso dos surdos, a Língua Portuguesa escrita). Então, tomamos como principal eixo deste trabalho as relações que alunos surdos estabelecem entre as línguas, sem deixar de considerar essas condições por nós observadas. 
http://dx.doi.org/10.5902/1984686X42625

Com o intuito de provocá-los no processo de letramento em Língua Portuguesa, construímos estratégias de trabalho assim como faz um "Mestre Ignorante" (RANCIÈRE, 2015). Dessa forma, seguindo Kohan (2003), o trabalho foi construído:

[...] como o exercício de um mestre que se interroga a si mesmo, a leitura de O mestre ignorante pode ser um belo trabalho de emancipação, em um dos sentidos que Rancière confere à palavra, em seu livro: forçar uma capacidade ignorada ou negada a desenvolver todas as consequências desse reconhecimento. Exercício emancipatório de leitura que nos força a pôr em questão o modo e o sentido com que ensinamos, as forças que nos movem a fazê-lo, as apostas políticas que, conscientemente ou não, afirmamos em nossa prática. Emancipatório é o exercício, se nos permite, ao final das contas, de educar sem subestimar ninguém - começando por não subestimarmos a nós próprios (KOHAN, 2003, p. 224).

Nessa perspectiva, para que se possa proporcionar a aquisição da leitura e da escrita da língua portuguesa para pessoas surdas, de forma emancipadora, há que se respeitar que as imagens, nesse processo, assumem uma função preponderante e que o aprendizado de Libras e da Língua Portuguesa, ocorrem em perspectivas distintas. Esta é linear e aquela é simultânea como afirma Felipe (1989) em seu texto "Bilinguismo e surdez". Logo, a concepção de mundo de um usuário de Língua de Sinais é diferente da concepção de um falante de língua oral-auditiva, pois, conforme já apontado no início desse texto; em Libras, dois sinais podem ser reproduzidos ao mesmo tempo, enquanto em línguas oraisauditivas os signos estão presos à linearidade dos significantes. Sendo assim, Lebedeff (2010) ao relatar suas experiências em oficinas de letramento visual com professores surdos, nos mostra que os textos em Língua Portuguesa, quando desenvolvidos em propostas educativas baseadas na visualidade da surdez, devem respeitar a experiência visual dos surdos. Essa foi a primeira lição que nos direcionou para a busca de emancipação no exercício da docência. Ou seja, o princípio de que:

À maneira de Perseu eu deveria voar para outro espaço. Não se trata absolutamente de fuga para o sonho ou o irracional. Quero dizer que preciso mudar de ponto de observação, que preciso considerar o mundo sob outra ótica, outra lógica, outros meios de conhecimento e controle (CALVINO, 1990 p.19).

Nós, professores, sabemos que as pessoas têm diferentes maneiras de aprender, de pensar ou fazer uma mesma tarefa, mesmo que estejam todas inseridas no mesmo contexto. As pessoas surdas também necessitam de metodologias diferenciadas que devem ser usadas por professores nas aulas, respeitando a suas singularidades linguísticas. Nem todos os surdos partem do mesmo ponto no ato de aprender e não dispõem dos mesmos recursos para isso. 
http://dx.doi.org/10.5902/1984686X42625

\section{Aprendendo com o apoio da Libras}

Conforme já apontado na metodologia, esta pesquisa teve como proposta de letramento, uma abordagem visual em que os textos em Língua Portuguesa foram apresentados aos alunos surdos através de possibilidades estéticas sob as quais a leitura e a escrita da pessoa surda tivessem como ponto de apoio a língua de sinais, já que os sujeitos sociais atuam no mundo por intermédio de uma língua através da qual realizam suas interações sociais e constroem sentidos próprios com a vida.

Ao longo de parte do processo de letramento dos surdos, constatamos a necessidade de uma reflexão sobre o processo de ensino-aprendizagem buscando identificar alguns porquês das dificuldades de aquisição de uma segunda língua, o Português escrito.

A proposta de apresentar textos em Língua Portuguesa sob uma estética visual é uma das inúmeras possibilidades de letramento, mas não podemos reduzir a complexidade do método de ensino-aprendizagem como fim em si mesmo, posto que aprender é algo que transcende o saber.

Entendemos 0 aprender como $o$ ato que nos conecta com a vida, processo que nos acompanha ao longo de nossa existência como o curso de um rio sem que possamos precisar sua nascente nem sua foz. Dessa forma, as propostas de ensino, se vistas como método que se encerra em si mesmo, restringiriam o pensamento, pois se apresentariam como verdades, respostas prontas para qualquer experiência em letramento visual.

O método é um artifício pelo qual reencontramos a natureza do pensamento, aderimos a essa natureza e conjuramos o efeito das forças estranhas que alteram e nos distraem. Pelo método nós conjuramos o erro. Pouco importa a hora e o lugar se aplicamos o método: ele nos faz penetrar no domínio do "que vale em todos os tempos, em todos os lugares (DELEUZE, 1962, p. 118).

A reflexão aqui apresentada busca enriquecer-se com 0 pensamento sobre 0 processo de letramento, sem o intuito de estabelecer o que é verdade ou erro. Busca-se pensar ativamente, mais do que a práxis, a produção de sentidos que é própria de toda experiência estética ${ }^{4}$, uma visão de educação e do agir, numa compreensão que desnaturaliza relações simplistas entre o homem e a vida, geralmente concebidas como fruto de uma dialética que encontra uma síntese entre homem/sociedade (DELEUZE, 2003).

Nesse sentido, passamos a investir um esforço para escapar dos objetivismos que nos conduzem a leis gerais de compreensão sobre como ocorrem os processos de 
http://dx.doi.org/10.5902/1984686X42625

aprendizagem, mas com o intuito de produzir intensidades cujos efeitos emancipem crianças e jovens em seus processos formativos.

Mais do que dominar, escolher, capacitar pessoas para o processo de ensinoaprendizagem da Língua Portuguesa, é fundamental que todos os envolvidos se libertem de suas castas, desnudem-se e se percebam em situação de igualdade.

O professor de Língua Portuguesa, ao se perceber aquele que também não sabe a resposta de sua busca, equipara-se ao aluno surdo, que também desconhece a resposta. Nesse processo de equivalência pelo desconhecido, a hierarquia não existe e os interlocutores têm seus discursos em situação de igualdade, de forma que "O que the importava era a cascata de refutações, era a arte que uns e outros empregavam para exprimir o que queriam dizer. " (RANCIĖRE, 2015, p. 187).

Sob esse ponto de vista, no processo de letramento em Língua Portuguesa objetivase o pensamento criador, na sua singularidade, sem que se tenha o controle em relação ao que será feito com o signo emitido por todos os envolvidos no ato de elocução. Espera-se que o aluno surdo seja capaz de emancipar-se, conceber-se em sua ação criativa e estabelecer inúmeras correlações necessárias para que possa construir seu pensamento, e, como diz Gallo (2012), aprender, apesar do que se ensina: "Aprender, pois, como acontecimento, como presença espaço/temporal, como processo, como passagem. (GALLO, 2012, p.7)

De acordo com Rancière (2015, p. 44), "O aluno deve ver tudo por ele mesmo, comparar incessantemente e sempre responder à tríplice questão: o que vês? O que pensa disso? O que fazes com isso? E assim, até o infinito". Assim como na obra de Rancière, nesta pesquisa, não se busca ensinar, mas sim entender como aluno pode reconhecer na arte da distância, ou seja, a capacidade que o mestre tem de reconhecer a distância entre a matéria e o sujeito a instruir, à distância, também, entre aprender e compreender.

A inspiração pela linguagem verbal e linguagem não verbal da literatura ocorre justamente para que o aluno possa, individualmente ou com seu professor, se servir de estratégias, correlações pessoais que o levem a se lançar, a mergulhar na leitura e na escrita como processo libertador de criação. O Ensino Mútuo, prevê, segundo o personagem Jacotot de Rancière (2015), que cada ignorante possa se fazer, para outro ignorante, um mestre que revelaria a ele seu poder intelectual (RANCIÈRE, 2015, p.37).

Neste livro, $O$ mestre ignorante, as lições de Jacotot ajudaram rapidamente os estudantes, mas vale ressaltar que um bom número ignorava o francês e Jacotot, por sua 
vez, ignorava totalmente o holandês. Foi essa perspectiva que experenciamos na pesquisa. À medida que dispusemos livros de literatura em linguagem verbal e linguagem não verbal aos estudantes surdos, almejávamos que cada um, ao seu tempo, segundo suas experiências subjetivas, pudesse se emancipar e buscar caminhos para suas reflexões individuais. Assim como eles, também ignorávamos o exato caminho a ser percorrido por cada um no processo de leitura e escrita. E assim caminhamos, como no exemplo que expusemos na metodologia. Nesse ensino mútuo, a cada experiência de um aluno, uma nova vivência também por nós e vice-versa.

Com essa perspectiva, o trabalho sobre o ato de escrever reverte-se sobre o estímulo, a esses alunos, no processo de leitura e escrita através de seus conhecimentos prévios para o desenvolvimento de caminhos que os auxiliem a observar, trilhar, escolher, inventar e, até mesmo, concluir que o registro em Língua Portuguesa escrita difere da perspectiva do registro em Libras.

A leitura é um processo aberto e, porque não dizer, poético, posto que não se pode abdicar da interferência do receptor na determinação dos sentidos conferidos àquilo que lê. Assumimos aqui que todo texto tem um caráter comunicacional e toda comunicação é exercida numa relação de alteridade, portanto, ao apresentarmos um texto em Língua Portuguesa a um aluno surdo, há que fazê-lo entender que a relação com a leitura não pode prescindir a existência de um outro, seja aquele que o escreveu ou quem o lê (RANCIÈRE, 2015).

\section{Conclusão}

Considerando esses pressupostos, concluímos que quanto maior o leque de possibilidades e experiências vivenciadas pelo leitor, maior as condições para ele discernir, escolher e se identificar com o texto analisado, apreciado, conhecido, estudado. Faz-se necessário pensar sobre esses leitores e como podem se tornar autores de suas escritas.

É bom lembrar que o aluno não aprende e não pensa só na escola. Ele faz parte, se constitui nas diferentes instituições e instancias sociais. Para o processo de formação integral desse aluno, é fundamental a clareza sobre a importância de uma educação realizada em um processo global, em que não haja uma hierarquização do saber, mas sim um rizoma5 de relações a ser considerado na análise de todo processo de construção desse pensar. 
O pensamento, de acordo com Gallo (2008) não é único, nem unitário, nem homogêneo. Analisar as palavras e imagens de nossas escutas, não se tratou apenas de dar tratamento aos registros desses signos, foi muito mais uma tentativa de cartografar esse processo. Essas palavras ou imagens vão além do registro em si. Elas são "o movimento do pensamento" como afirma Gallo, ao citar Deleuze (2008). A cartografia desses registros nos permitiu observar a criação do ato de pensar. Sendo assim, este trabalho teve, também, a intenção de produzir caminhos possíveis desses processos através de registros manifestos do ato de pensar e, a partir disso, a construção das reflexões sobre o aprender que transcende o que se faz materialmente na sala de aula.

\section{Referências}

BAKHTIN, Mikhail. Marxismo e Filosofia da Linguagem. São Paulo: Hucitec. 1990.

CALVINO, Italo. Seis propostas para o próximo milênio: lições americanas. Tradução de Ivo Barroso. São Paulo: Companhia das Letras, 1990

DELEUZE, Gilles. Diferença e Repetição. $2^{\mathrm{a}}$ ed. Rio de Janeiro: Graal, 1998.

DELEUZE, Gilles. Proust e os Signos. $2^{\mathrm{a}}$ ed. Rio de Janeiro: Forense Universitária, 2003.

DELEUZE, Gilles. Nietzsche et la Philosophie. Paris: PUF, 1962.

DELEUZE, Gilles. GUATARRI, Félix. Mil platôs. v. 1. Ed. 34. Rio de Janeiro: Letras, 2011.

DOLLE, Jean-Marie. Linguagem e Pensamento. In: Jean Piaget no século XXI escritos de epistemologia e psicologia genéticas. Marília: São Paulo. Cultura Acadêmica: Oficina Universtária, 2011.

EL KHOURI, Mauro Michel. Rizoma e Educação: contribuições de Deleuze e Guattari. ABRAPSO, 2011. In:

http://www.abrapso.org.br/siteprincipal/images/Anais_XVENABRAPSO/198.\%20rizoma\%2 0e\%20educa\%C7\%C3o.pdf - Acesso em: 25/06/2017.

FELIPE, Tanya A. Bilinguismo e surdez. In: Trabalho Linguística Aplicada, Campinas, (14): 101-112, julho/dezembro. 1989.

FERNANDES, Eulália. Problemas Linguísticos Cognitivos do Surdo. Rio e Janeiro: Agir, 1990.

FERNANDES, Eulalia; RIOS, Katia Regina. Educação com bilinguismo para crianças surdas. Intercâmbio, vol.VII, 1998. 
GALLO, Sílvio. Filosofia e o exercício do pensamento conceitual na educação básica. In: Educação e Filosofia. Uberlândia, v.22, n. 44, p. 55-78, jul/dez, 2008.

GALLO, Sílvio. As múltiplas dimensões do aprender. In: COEB 2012. Congresso de Educação Básica: Aprendizagem e Currículo.

GOLDFELD, Márcia. A criança surda: Linguagem e cognição numa perspectiva sóciointeracionista. 2ª ed. São Paulo: Plexus Editora, 2002.

KOHAN, Walter Omar. Três lições de Filosofia da Educação. Educação \& Sociedade, Campinas, vol. 24, n. 82, p. 221-228, abril 2003. Disponível em:

http://www.scielo.br/pdf/es/v24n82/a12v24n82.pdf. Acesso em: 25/06/2017.

LEBEDEFF, Tatiana Bolívar. Aprendendo a ler "com outros olhos": relatos de oficinas de letramento visual com professores surdos. Cadernos de Educação. FaE/PPGE/UFPel, Pelotas [36]: 175-195, maio/agosto. 2010.

MEGALE, Antonieta Heyden. Bilinguismo e educação bilíngue - discutindo conceitos. Revista Virtual de Estudos da Linguagem - ReVEL. V. 3, n. 5, agosto de 2005. ISSN 1678-8931 [www.revel.inf.br].

MOSTAFA, Solange Puntel. Vygotsky e Deleuze: um diálogo possível? Campinas: Alínea Editora, 2008.

PASSOS, Eduardo; KASTRUP, Virgínia.; ESCÓSSIA, Liliana. (Orgs.). Pistas do método da cartografia: pesquisa-intervenção e produção de subjetividade. Porto Alegre: Sulina, 2009.

PASSOS, Felipe Garcia. A cartografia digital na geografia escolar brasileira: contexto, características e proposições. PhD Thesis. Universidade de São Paulo.2017.

PENNINGS, Anthony J. (SD). What is Visual Literacy? http:// www.academic.marist.edu/pennings/viswhatis.htm Acesso em: 13/11/2004, p.20.

QUADROS, Ronice Müller de. Educação de surdos: aquisição da linguagem. São Paulo: Artmed, 1997.

RANCIÈRE, Jacques. O mestre ignorante - cinco lições sobre a emancipação intelectual. Trad. Lilian do Valle. 3 ed. 4ª reimp. Belo Horizonte, Autêntica Editora, 2015.

SÁNCHEZ, Carlos. La Educación de los Sordos en un Modelo Bilingue. Mérida, Venezuela, 1991.

SÁNCHEZ, Carlos. La increible y triste historia de la sordera. Merida, Venezuela: CEPROSORD, 1990.

SAUSSURE, Ferdinand de. Curso de linguística geral. 4. ed. São Paulo: Ed. Cultrix, 1995. 
http://dx.doi.org/10.5902/1984686X42625

SKLIAR. Carlos. (org.) A surdez: um olhar sobre as diferenças. Porto Alegre: Editora Mediação, 1998.

VYGOTSKY, Lev Semionovitch. Pensamento e Linguagem. São Paulo. Martins Fontes, 2000.

\section{Notas}

${ }^{1}$ Segundo Pennings, Letramento Visual é a área de estudo que lida com o que pode ser visto e como se pode interpretar o que é visto (PENNINGS, 2004, p.20).

2 Bilinguismo composto é aquele que tem uma única representação cognitiva para duas traduções equivalentes (SPOLSKY, 2004, p.48).

${ }^{3}$ Bilinguismo coordenado o indivíduo que tem representações diferentes para as duas traduções equivalentes (SPOLSKY, 2004, p. 48).

${ }^{4} \mathrm{~A}$ experiência estética aqui compreendida é uma experiência subjetiva, a qual tomo como princípio a etimologia da palavra estética do grego - aisthésis: percepção, sensação, sensibilidade. Portanto, a Experiência Estética está relacionada ao conceito de "Acontecimento" formulado por Deleuze - algo que nos passa, o que nos acontece, que nos toca dando novo sentido às coisas. Podemos dizer que através dessa experiência somos modificados.

${ }^{5}$ Segundo Deleuze e Guatarri na obra: Mil Platôs: "O rizoma é um modelo de resistência ético-estético-político, trata-se de linhas e não de formas. Por isso o rizoma pode fugir, se esconder, confundir, sabotar, cortar caminho. Não que existam caminhos certos, talvez o correto seja o mais intensivo (e não o caminho do meio). As linhas de fuga são aquelas que escapam da tentativa totalizadora e fazem contato com outras raízes, seguem outras direções. Não é uma forma fechada, não há ligação definitiva. São linhas de intensidade, apenas linhas de intensidade". https://razaoinadequada.com/2013/09/21/deleuze-rizoma/

\section{Correspondência}

Ângela Simone Mattos Esteves - Universidade Federal Fluminense, Rua Miguel de Frias, no 9, Icaraí, Niterói, Rio de Janeiro - Brasil.

CEP: $24220-900$

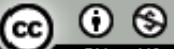
International (CC BY-NC 4.0) 